\title{
Shape memory effect and mechanical properties of cyanate ester-polybutadiene epoxy copolymer
}

\author{
Wang Kun • Zhu Guangming • Niu Lei • Wang Yongkun • \\ Liu Zhe
}

Received: 17 July 2013 / Accepted: 10 February 2014 / Published online: 7 March 2014

(C) The Author(s) 2014. This article is published with open access at Springerlink.com

\begin{abstract}
A type of thermal-induced shape memory polymer was fabricated using a new epoxy resin-polybutadiene epoxy (PBEP) and bisphenol A-type cyanate ester in different mass ratios. Mechanical performance, thermal properties, and shape memory behaviors were investigated systematically. This polymer system presented good shape memory properties. The deformation recovery speed increased with the increase in the amount of PBEP. The maximum deformation recovery speed was $0.0128 \mathrm{~s}^{-1}$, and the minimum value was $0.0073 \mathrm{~s}^{-1}$. The deformation recovery rate was almost $100 \%$.
\end{abstract}

Keywords Shape memory effect · Thermal-induced · Bisphenol A-type Cyanate Ester · Polybutadiene epoxy resin

\section{Introduction}

Shape memory polymer (SMP) is a novel type of smart polymer that can rapidly return to its original shape from a temporary shape under appropriate stimuli such as temperature, light, electric field, magnetic field, $\mathrm{pH}$, specific ions, or enzymes.

Compared with shape memory metallic alloys and shape memory ceramics, SMPs possess the advantages of light weight, low cost, good processability, high shape deformability and recoverability, and tailored switch temperature [1-10]. Since the 1990s, SMPs have been increasingly developed and widely applied in smart textiles and apparels [11, 12], intelligent medical devices [13-15], and self-deployable structures in spacecrafts [16-20].

W. Kun $(\bowtie) \cdot$ Z. Guangming $(\bowtie) \cdot$ N. Lei $\cdot$ W. Yongkun $\cdot$ L. Zhe Department of Applied Chemistry, School of Science, Northwestern Polytechnical University, Xi'an 710129, China

e-mail: wangkun0521@163.com

e-mail: gmzhu@nwpu.edu.cn
Research on SMP locally and abroad is relatively rare, but some deformation theories exist, such as the relationship between shape memory effect and shape polymer structure [21]: the shape memory polymer structure includes a stationary phase that can fix the initial state and a reversible phase that can soften and reversibly solidify with temperature. In addition, several scholars [22-25] have developed a series of models that can describe the mechanical performance of shape memory effect. For example, the mechanical viscoelastic model can be used to describe the shape memory performance of SMP; we can also use the evaluation method of shape memory alloys [26] to evaluate the shape memory behavior of SMP. Moreover, we can prepare and adjust SMP through copolymerization, cross-linking, and other methods.

In some studies, such as intelligent medical instruments test, lower deformation speed lead to the test failure. Again, for example, the deformation fixity and deformation recovery speed impact the accomplishment and accuracy of the space deployable structure experiment. In theory, there is something to do with the elastic part of shape memory polymer system, namely reversible phase which can soften and solidify reversibly with the stimulus. Consequently, the choice of reversible phase in the system is significant to the deformation fixity and recovery of shape memory polymer.

In this study, we selected the bisphenol A-type cyanate ester (BACE) and polybutadiene epoxy (PBEP) resin copolymerization systems, because PBEP consists of long, flexible, aliphatic chains that can act as the reversible phase, whereas the BACE cyclization reaction ring can act as the stationary phase. This provides the theoretical basis for preparing SMP. The copolymerization reduced the glass transition temperature $\left(\mathrm{T}_{\mathrm{g}}\right)$ of $\mathrm{BACE}$ and improved its mechanical performance. BACE resin and PBEP have excellent compatibility and can mix in any mass ratio. These characteristics can result in great improvement in 
processing properties and operability. In addition, SMP that is made of BACE/PBEP system is reported firstly in this field here.

\section{Experimental work}

Materials

BACE white crystal with purity of more than $99.5 \%$ and molecular weight of 278 (general schematic chemical structure formula: $\mathrm{R}-\mathrm{O}-\mathrm{C} \equiv \mathrm{N}$ ) was obtained from Zhejiang Victory Biological Chemical Co., Ltd. PBEP amber sticky liquid with a viscosity-average molecular weight of 2,500 and epoxy value of $117 \mathrm{~g} / \mathrm{mol}$ (general schematic chemical structure formula: $+\mathrm{CH}_{2}-\mathrm{CH}-\mathrm{CH}-\mathrm{CH}_{2}-\mathrm{CH}_{2}-\mathrm{CH}_{\mathrm{O}} \mathrm{CH}-\mathrm{CH}_{2}-\mathrm{CH}_{1}-\mathrm{CH}_{2}-\mathrm{CH}_{1}-\mathrm{CH}_{2}-\mathrm{CH}_{1}-\mathrm{CH}_{2}-\mathrm{丁}_{\mathrm{n}}$

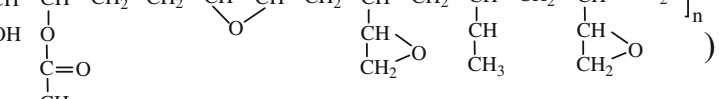
was obtained from Wuhan ShiZiShan Paint Manufacture Co., Ltd.

Preparation of the SMP casting

BACE was mixed with PBEP in five different mass ratios: 1:0.8, 1:0.9, 1:1, 1:1.1, and 1:1.2 (BACE/PBEP). We named them PBEP-0.8, PBEP-0.9, PBEP-1, PBEP-1.1, and PBEP-1.2, respectively. The curing process was $100{ }^{\circ} \mathrm{C} / 3 \mathrm{~h}+120{ }^{\circ} \mathrm{C} / 2 \mathrm{~h}$ and the post process was $180^{\circ} \mathrm{C} / 1 \mathrm{~h}$.

\section{Characterization}

\section{Gel time}

The specimen for the resin system was placed on a steel surface at constant temperature from $100{ }^{\circ} \mathrm{C}$ to $180{ }^{\circ} \mathrm{C}$. The resin system reacted quickly with increasing temperature. In this experiment we chose $100^{\circ} \mathrm{C}, 120^{\circ} \mathrm{C}, 140^{\circ} \mathrm{C}, 160^{\circ} \mathrm{C}$, and $180^{\circ} \mathrm{C}$

At the beginning, the resin system had good flow ability, just like water. As the reaction proceeded, the gelation appeared, which meant completion of the curing. We confirmed this by using a knife dipped in the liquid constantly until gelling. Gel time is defined as the interval between the time the resin is initially set and the time when its gel wire drawing ability appears.

\section{Fourier-transform infrared spectroscopy (FTIR)}

We picked the cured PBEP-1 system to dissolve in acetone solution and prepared the samples for FTIR analysis by casting thin films on $\mathrm{KBr}$ discs. We used a glass rod to daub the solution on the $\mathrm{KBr}$ discs and dried them. In this way we can get thinner film with higher transmittance.
FTIR spectra were recorded on a Perkin-Elmer spectrum GXA model in the range of $4,000 \mathrm{~cm}^{-1}$ to $5,500 \mathrm{~cm}^{-1}$ with a resolution of $4 \mathrm{~cm}^{-1}$.

\section{Bending tests}

Bending tests were conducted at room temperature according to a three-point bend method using a bending test instrument (SANS Power Test v3.0, Shenzhen SANS Material Test Instrument Co., Ltd., China). We prepared 5 samples for each BACE-PBEP mass ratio cured system. The strain rate was $2 \mathrm{~mm} \mathrm{~min}^{-1}$. Bending strength denotes the three-point bend strength in MPa. It is defined as $3 \mathrm{Pl} / 2 \mathrm{bh}^{2}$, where $\mathrm{P}$ denotes the fracture load in $\mathrm{N}$ and 1 denotes the distance between the support bearings in $\mathrm{mm}$; $\mathrm{b}$ denotes the width of the test piece in $\mathrm{mm}$, and $\mathrm{h}$ denotes the height of the test piece in $\mathrm{mm}$. Bending strength results were recorded during the experiment.

\section{Dynamic thermo-mechanical analysis}

$\mathrm{T}_{\mathrm{g}}$ values were determined through dynamic thermomechanical analysis using DMA Q800 at a frequency of $1 \mathrm{~Hz}$ and a heating rate of $2{ }^{\circ} \mathrm{C} / \mathrm{min}$.

\section{Shape memory properties}

Shape memory tests were conducted using the following procedure. First, heat up the specimen to the transformation temperature $\mathrm{T}_{\text {trans }}\left(\mathrm{T}_{\text {trans }}=160{ }^{\circ} \mathrm{C}\right)$ and hold for $5 \mathrm{~min}$. As shown in Fig. 1, the sample was deformed to an angle of $\theta_{\mathrm{i}}\left(\theta_{\mathrm{i}}=\Pi\right)$. Under constant force, the deformation rapidly cooled down to room temperature. Consequently, the deformation was restored. The deformation recovery spee'sd corresponding temperature was defined as $\theta_{\mathrm{i}} / \mathrm{t}$, and the deformation recovery rate was defined as $\left(\theta_{\mathrm{i}}-\theta_{\mathrm{f}}\right) / \theta_{\mathrm{i}} \times 100 \%$.

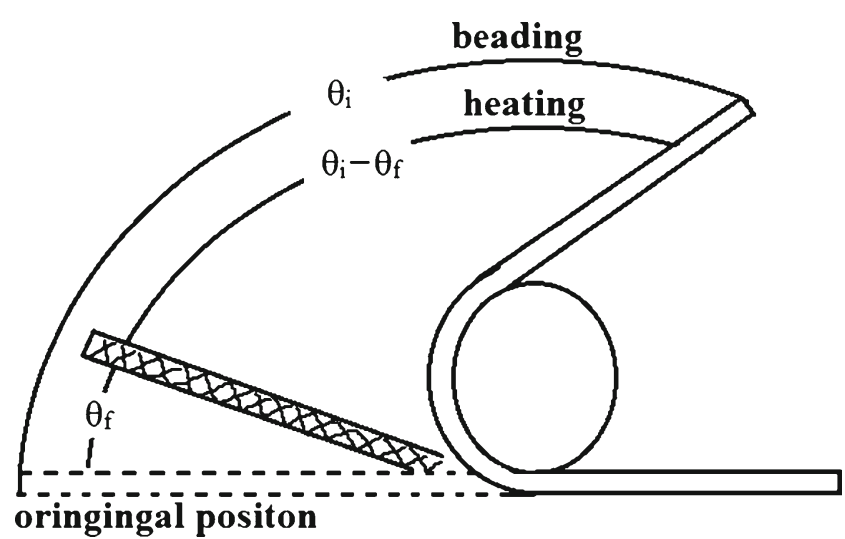

Fig. 1 Bending deformation model of shape memory effect 


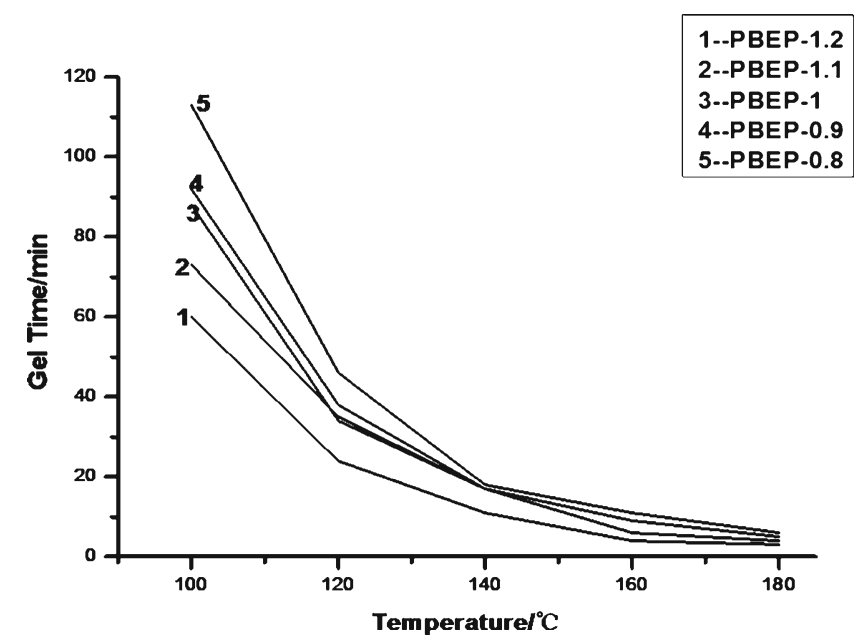

Fig. 2 Gel time of the different copolymerization systems

\section{Results}

Chemical reactivity of the copolymerization system

Figure 2 showed the gel time of the copolymerization system at different mass ratios. The graph showed that the gel time of the copolymerization systems with different mass ratios decreased as the temperature increased. As shown in Fig. 2, the specimen PBEP-0.8 would gel in $2 \mathrm{~h}$ at $100{ }^{\circ} \mathrm{C}$, but would gel in only $6 \mathrm{~min}$ at $180{ }^{\circ} \mathrm{C}$.

In addition, at the same temperature, the gel time of all the copolymerization systems decreased as PBEP increased. This result indicates that both the temperature and the amount of PBEP had a significant influence on the gel time of the copolymerization system.

According to the gel time, we can pick the most suitable temperature for curing. The least time stands for the quickest reaction speed. For the preparation of the resin system, this is significant. The final curing process was fixed at $100{ }^{\circ} \mathrm{C} / 3 \mathrm{~h}+$ $120^{\circ} \mathrm{C} / 2 \mathrm{~h}$, and the post process was $180^{\circ} \mathrm{C} / 1 \mathrm{~h}$.

\section{FTIR characterization}

As shown in Fig. 3, after the curing process of $100{ }^{\circ} \mathrm{C} / 3 \mathrm{~h}+$ $120{ }^{\circ} \mathrm{C} / 2 \mathrm{~h}$, the BACE group $(2,270)$ of the copolymerization system rapidly diminished, followed by an increase of the triazine ring $(1,369)$. However, less epoxy group (815) consumption was observed. These results indicate that at the beginning of the reaction, the main reaction was the cyclization reaction of BACE resin, with less epoxy group inserted into the triazine ring [26]. The reaction equations are as follows:

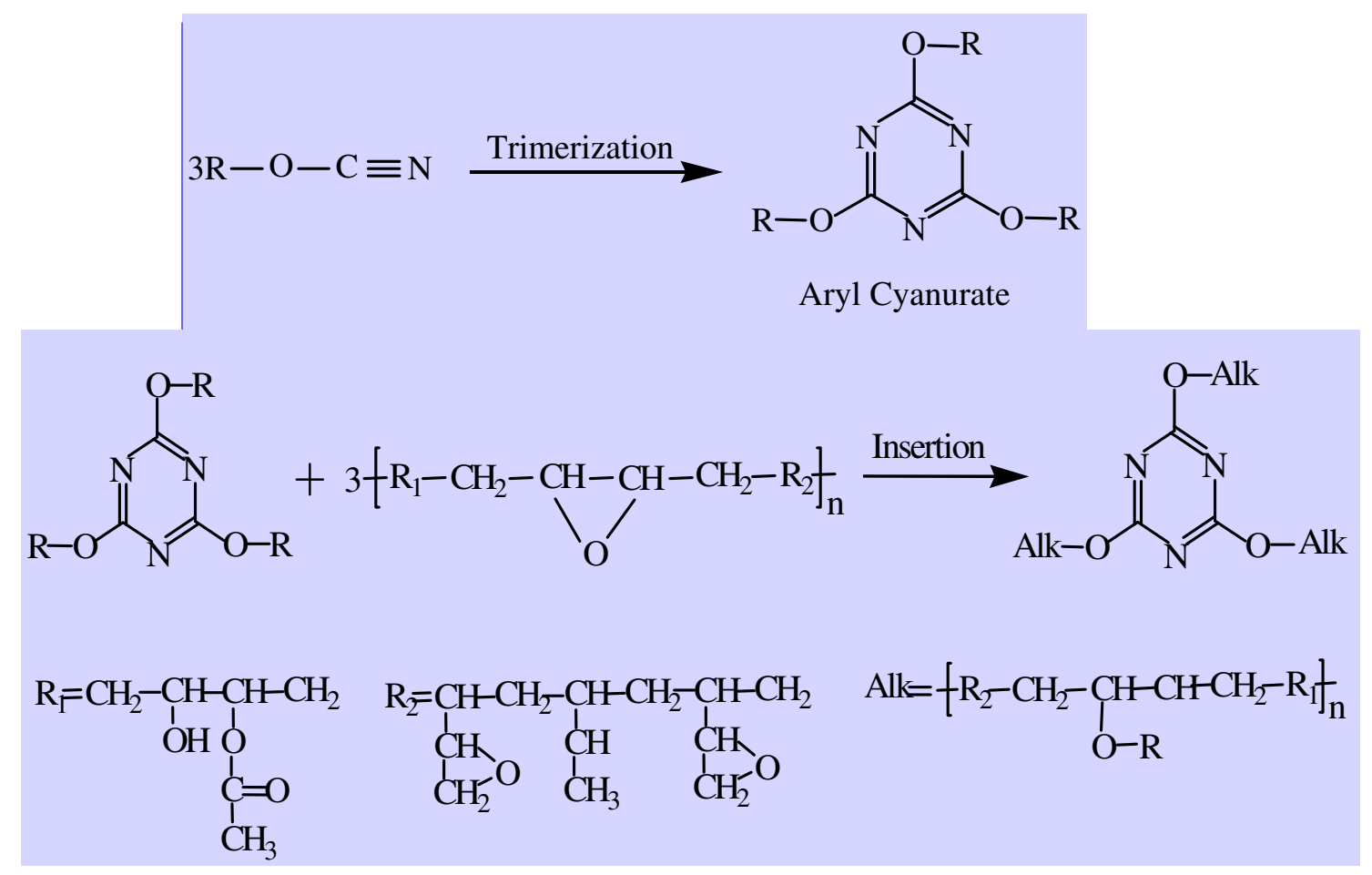

In addition, after post-processing at $180{ }^{\circ} \mathrm{C} / 1 \mathrm{~h}$, the BACE groups $(2,270)$ and the epoxy groups (815) almost disappeared, which indicated that the BACE groups and the epoxy groups had completely reacted. Furthermore, the triazine ring $(1,369)$ began to decline, with the consumption of the epoxy groups and the increase in the 
oxazoline ketone ring $(1,680)$. Thus, the latter period of the curing mainly involved the epoxy group insertion into the reformation ring and the generation of the oxazoline ketone ring [27]. The reaction equations are as follows:

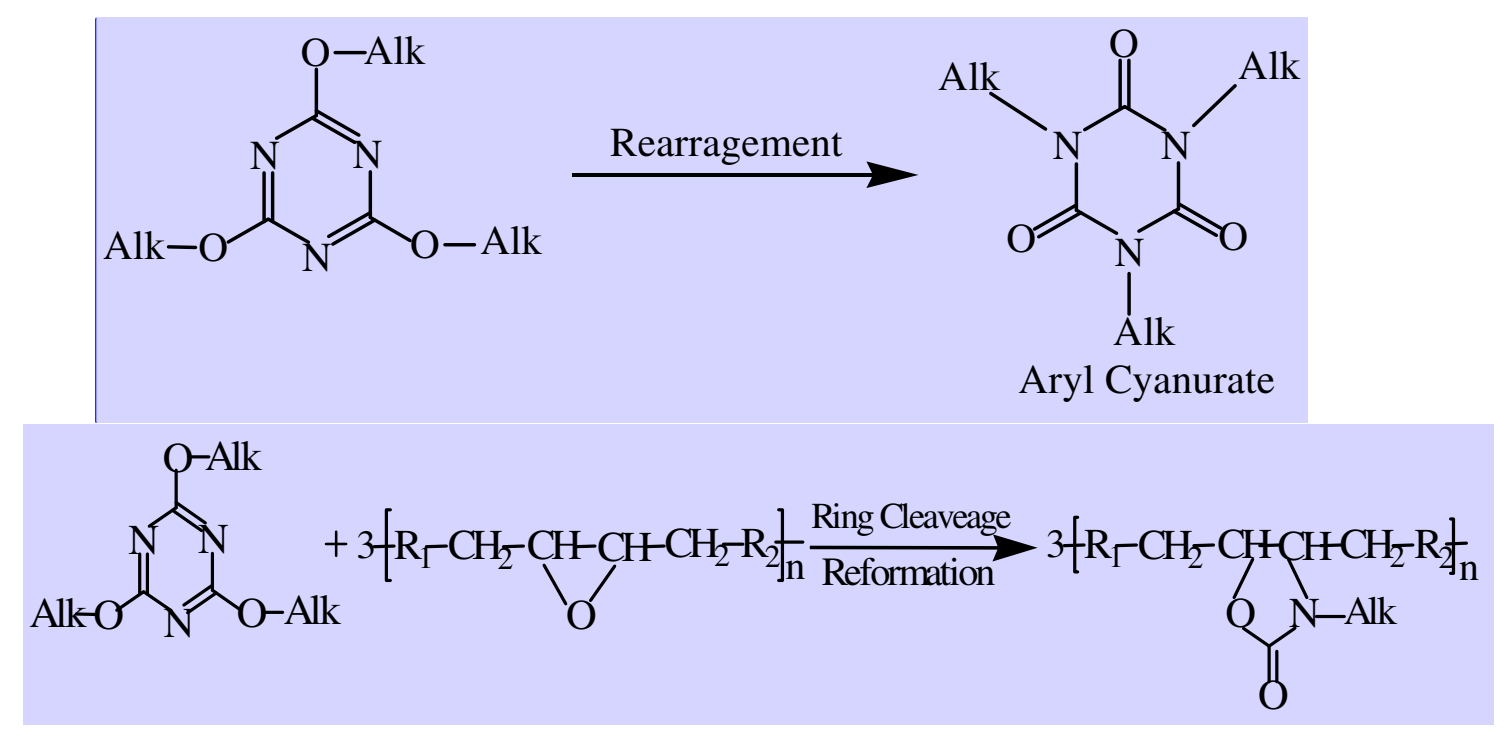

\section{Mechanical properties}

Figure 4 showed the bending strength of the copolymerization system with different mass ratios at room temperature. The graph indicated that an increase in PBEP resin resulted in a decrease in bending strength. Theoretically, when BACE has been completely solidified into a neat structure, it contains triazine and oxazoline ketone rings, which possess higher crystallinity and greater cross-linking density. However, PBEP consists of a flexible long-carbon chain structure, which destroys the molecular structure of BACE, leading to a lower cross-linking density. As a result, stiffness was reduced, and the bending strength decreased.

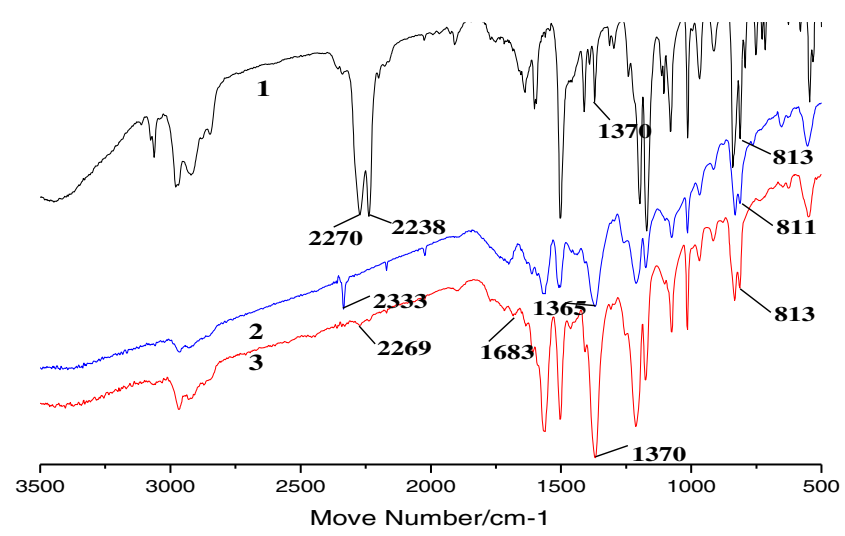

Fig. 3 FTIR of PBEP-0.8 before and after curing. (1) before curing, (2) after curing $\left(100{ }^{\circ} \mathrm{C} / 3 \mathrm{~h}+120{ }^{\circ} \mathrm{C} / 2 \mathrm{~h}\right),(3)$ after curing $\left(100{ }^{\circ} \mathrm{C} / 3 \mathrm{~h}+\right.$ $\left.120^{\circ} \mathrm{C} / 2 \mathrm{~h}\right)$, and post-process $\left(180^{\circ} \mathrm{C} / 1 \mathrm{~h}\right)$
Thermal property and shape memory effect

Figure 5 showed the Tan Delta curves for the different copolymerization systems. The temperature at the maximum value of Tan Delta indicates $\mathrm{T}_{\mathrm{g}}$. The $\mathrm{T}_{\mathrm{g}}$ of PBEP-0.8, PBEP-1, and PBEP-1.2 were 165,148 , and $136{ }^{\circ} \mathrm{C}$, respectively. Apparently the $T_{g}$ of the copolymerization system gradually decreased with the increase in content of the epoxy resin. As it is known to all, neater structure and higher cross-linking density lead to a higher glass transition temperature. While in the BACE-PBEP copolymerizaion system, the cyclization reaction of $\mathrm{BACE}$ contained the neat structure (triazine rings and oxazoline ketone rings). However, PBEP resin consists of

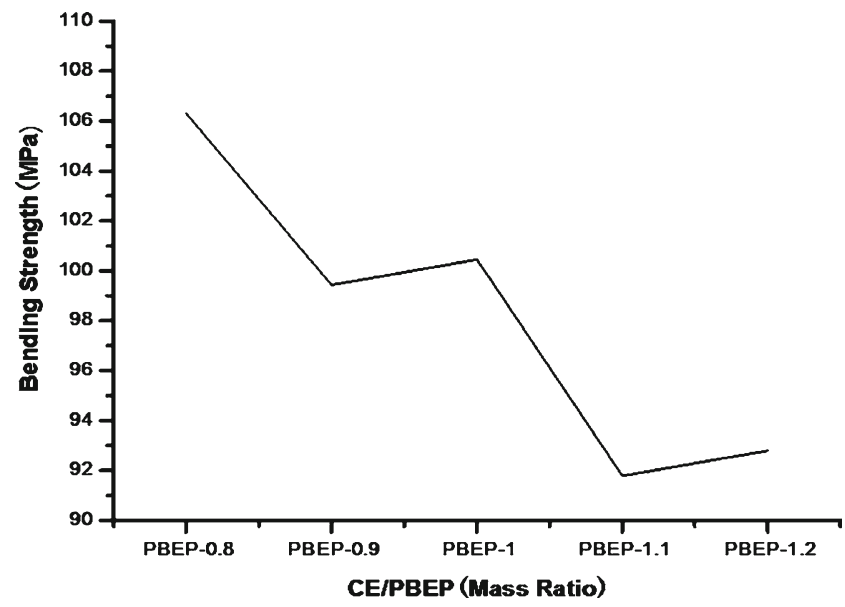

Fig. 4 Bending strength at room temperature 


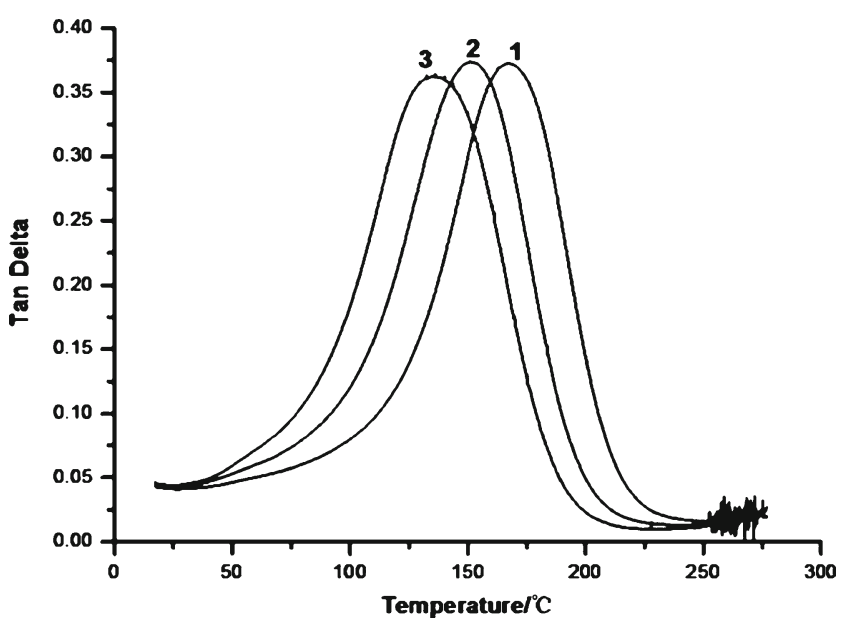

Fig. 5 Tan Delta curves of PBEP-0.8 (1), PBEP-1 (2) and PBEP-1.2 (3)

a flexible long-carbon chain structure. The neat structure of the copolymerization system was destroyed due to the introduction of PBEP into the BACE, and the cross-linking density decreased. Subsequently, the glass transition temperature decreased.

Figure 6 illustrated the recovery process of the PBEP-1 copolymerization system. The sample automatically recovered to $0^{\circ}$ from $180^{\circ}$ within $245 \mathrm{~s}$. It is the stationary phase and the reversible phase that made the polymer possess good shape memory effect. The stationary phase (just like a crosslinking point) fixes the initial shape, while the reversible phase (elastic chain) transforms reversibly with temperature. Further, the deformation recovery is ascribed to the release
Table 1 Shape memory results

\begin{tabular}{llll}
\hline $\begin{array}{l}\text { Specimen } \\
\text { Number }\end{array}$ & $\begin{array}{l}\text { Deformation } \\
\text { Recovery } \\
\text { Time/s }\end{array}$ & $\begin{array}{l}\text { Deformation } \\
\text { Recovery } \\
\text { Speed/s }\end{array}$ & $\begin{array}{l}\text { Deformation } \\
\text { Recovery } \\
\text { Rate/\% }\end{array}$ \\
\hline PBEP-0.8 & 430 & 0.0073 & 99 \\
PBEP-0.9 & 299 & 0.0105 & 100 \\
PBEP-1.0 & 286 & 0.0109 & 100 \\
PBEP-1.1 & 252 & 0.0125 & 100 \\
PBEP-1.2 & 245 & 0.0128 & 100 \\
\hline
\end{tabular}

of the elastic chain, which is applied and memorized during the shape-fixing stages and the transformation, respectively. In the BACE-PBEP copolymerization system, the cured BACE contained a neat structure (triazine rings and oxazoline ketone rings), which can act as the stationary phase. What's more, PBEP resin consists of the flexible aliphatic chains which can act as the reversible phase. This simple deformation and fast recovery process could be applied in thermo-sensitive actuators.

Table 1 presented the comparison of shape memory effect at the deformation temperature of $160{ }^{\circ} \mathrm{C}$ for the copolymerization systems. The table showed that after the moderate crosslinking of BACE and PBEP, the copolymer exhibited good shape memory performance. As PBEP increased, the deformation recovery time became shorter, indicating that the deformation recovery speed was increasing. As PBEP increased, the flexibility of the copolymerization system increased and the
Fig. 6 Graphical abstract of shape memory effect

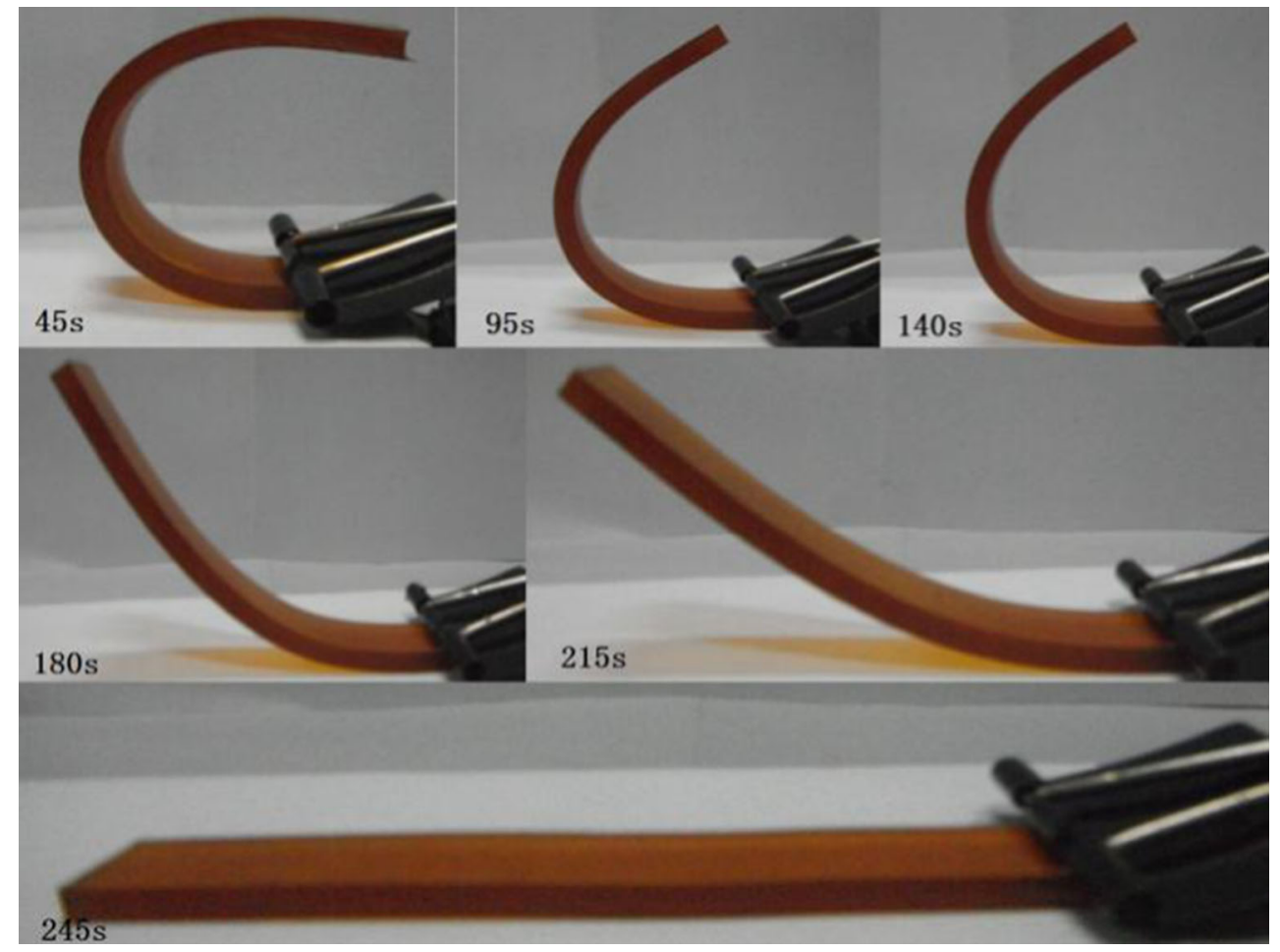


deformation recovery speed increased. Moreover, the table showed that the deformation recovery rate of the copolymerization system can be as high as almost $100 \%$.

\section{Conclusions}

In this experiment, we selected BACE and PBEP to prepare an SMP and tested it from the perspective of shape memory effect.

Through the analysis of bending strength, we found that the bending strength of the copolymer gradually decreased as the PBEP content increased. The deformation recovery speed showed a similar trend. The polymer possessed good mechanical properties and shape recovery characteristics that could be controlled by varying the matrix composition.

Based on the principles and the methods in this experiment, we wish to find types of polymer with better shape memory properties (such as higher deformation fixity and controllable deformation recovery speed and rate) which are suitable for processing smart thermal sensors and self-deployable structures. In the medical field or space exploration areas, especially when direct human intervention is hard to achieve, shape memory polymers can play a role in developing mediated or temporary shapes that are easier to manipulate. The polymer acts steadily and independently as long as the critical conditions are maintained, which means lower cost and higher operability.

Open Access This article is distributed under the terms of the Creative Commons Attribution License which permits any use, distribution, and reproduction in any medium, provided the original author(s) and the source are credited.

\section{References}

1. Hyashi S (1993) Properties and applications of polyurethane. Int Prog Urethanes 6:90-115

2. Tobushi H, Hashimoto T, Ito N, Hayashi S, Yamada E (1998) Shape fixity and shape recovery in a film of shape memory polymer of polyurethane series. J Intell Mater Syst Struct 9:127-136

3. Lin JR, Chen LW (1998) Study on shape-memory behavior of polyether-based polyurethanes. I. Influence of the hard-segment content. J Appl Polym Sci 69:1563-1574

4. Lin JR, Chen LW (1998) Study on shape-memory behavior of polyether-based polyurethanes. II. Influence of soft-segment molecular weight. J Appl Polym Sci 69:1575-1586

5. Wei ZG, Sandstrom R, Miyazaki S (1998) Shape-memory materials and hybrid composites for smart systems: Part I shape-memory materials. J Mater Sci 33:3743-3762

6. Lendlein A, Kelch S (2002) Shape-memory polymers. Angew Chem Int Ed 41:2034-2057

7. Yang JH, Chun BC, Chung Y-C, Cho JH (2003) Comparison of thermal/mechanical properties and shape memory effect of polyurethane block-copolymers with planar or bent shape of hard segment. Polymer 44:3251-3258

8. Hu JL, Ji FL, Wong YW (2005) Dependency of the shape memory properties of a polyurethane upon thermomechanical cyclic conditions. Polym Int 54:600-605

9. Liang C, Rogers CA (1997) One-dimensional thermomechanical constitutive relations for shape memory materials. J Intell Mater Syst Struct 8:285-302

10. Xie T, Rousseau IA (2009) Facile tailoring of thermal transition temperatures of epoxy shape memory polymers. Polymer 50:18521856

11. Meng QH, Hu JL, Zhu Y, Lu J, Liu Y (2007) Morphology, phase separation, thermal and mechanical property differences of shape memory fibers prepared by different spinning methods. Smart Mater Struct 16:1192-1197

12. Meng QH, Hu JL, Yeung LY (2007) An electro-active shape memory fiber by incorporating multi-walled carbon nanotubes. Smart Mater Struct 16:830-836

13. Lendlein A, Langer R (2002) Biodegradable, elastic shape-memory polymers for potential biomedical applications. Science 96:16731676

14. Metcalfe A, Desfaits A-C, Salazkin I, Yahiab L, Sokolowskic WM, Raymonda J (2003) Cold hibernated elastic memory foams for endovascular interventions. Biomaterials 24:491-497

15. Wache HM, Tartakowska DJ, Hentrich A, Wagner MH (2004) Development of a polymer stent with shape memory effect as a drug delivery system. J Mater Sci Mater Med 14:109-112

16. Abd EI-Mohdy HL (2013) Thermo-responsive behavior of radiationinduced poly(N-isopropylacrylamide)/polyethylene oxide nanocomposite. J Polym Res 20(8):206-211

17. Wu XL, Huang WM, Tan HX (2013) Characterization of shape memory via creeping and shape memory effect in ether-vinyl acetate copolymer (EVA). J Polym Res 20(8):150-159

18. Kim BK, Lee SY, Xu M (1996) Polyurethane having shape memory effect. Polymers 37:5781-5793

19. Jin ZX, Pramoda KP, Xu GQ, Goh SH (2001) Dynamic mechanical behavior of melt-processed multi-walled carbon nanotube/poly(methyl methacrylate) Composites. Chem Phys Lett 337:43-47

20. Hu JL, Ding XM, Tao XM (2001) Shape memory polymers and their applications to smart textile products. J Chin Text Univ 19:89-93

21. Biju R, Reghunadhan Nair CP (2013) Systhesis and characterization of shape memory epoxy-anhydride system. J Polym Res 20(2):82-97

22. Kalita H, Mandal M, Karak N (2012) Biodegradable solvent-induced shape memory hyperbranched polyurethane. J Polym Res 10:99829997

23. Huang WM, Zhao Y, Wang CC, Ding Z, Puranwadi H, Tang C, Zhang JL (2012) Thermo/chemo-responsive shape memory effect in polymer: a sketch of work mechanisms, fundamentals and optimization. J Polym Res 19(9):9952-9961

24. Kavitha, Revathi A, Sandhya R, Shylaja S, Dayananda GN (2012) Characterization of shape memory behavior of CYBN-epoxy resin system. J Polym Res 19(6):9894-9993

25. Radjabian M, Kish MH, Mohammadi N (2012) Structure-property relationship for poly(lactic acid)(PLA)filaments: physical, thermomechanical and shape memory characterization. J Polym Res 19(6): 9870-9886

26. Schmidt C, Sarwaruddin Chowdhury AM, Neuking K, Eggeler G (2011) Thermo-mechanical behavior of shape memory polymers, e.g., Teckflex ${ }^{\circledR}$ by $1 \mathrm{WE}$ Method: SEM and IR analysis. J Polym Res 18(6): 1807-1812

27. Huayu Q, Ling L, Guozheng L (2000) Research of Epoxy resin/ cyanate ester resin. Northwest Polytech Univ 01:1151-1154 